\title{
Farklı Yanlılık Parametreleri İçin Ridge GM Tahmin Edicilerinin Performanslarının Karşılaştırılması ${ }^{*}$
}

\section{Comparison of the Performances of Ridge GM Estimators for Different Biased Parameters}

\author{
Melike Işılar $^{1}$, Y. Murat Bulut ${ }^{2 *}$ \\ Geliş / Received: 09/02/2021 \\ Revize / Revised: 27/03/2021 \\ Kabul / Accepted: 30/03/2021 \\ ÖZ \\ Çoklu lineer regresyon modelinde yaygın olarak karşılaşılan problemler çoklu iç ilişki ve aykırı değer \\ problemleridir. Bu iki problemin eş anlı çözümleri için literatürde sağlam yanlı tahmin ediciler üzerine pek çok \\ çalışma mevcuttur. Bu tahmin edicilerden en yaygın kullanılanları sağlam Ridge tahmin edicileridir. Yanlılık \\ parametresine bağlı olan Ridge tahmin edicisine ilişkin günümüzde de pek çok çalışma yapılmaktadır. Yapılan \\ çalışmalarda yanlılık parametresinin performansı klasik Ridge tahmin edicisinde incelenmektedir. Bu çalışmada \\ her iki değişkende de aykırı değer olması ve çoklu iç ilişki probleminin ortak çözümü için önerilmiş olan Ridge \\ GM tahmin edicisinde literatürde daha önce önerilmiş olan yanl1l1k parametrelerinin performansları simülasyon \\ çalışması ve gerçek veri örneği üzerinde incelenmiştir.
}

Anahtar Kelimeler- Lineer Regresyon Modeli, Çoklu İç İlişki, Aykırı Değer, Ridge Regresyon, Yanlılık Parametresi

\begin{abstract}
In the multiple linear regression model, commonly encountered problems are multicollinearity and outlier problems. There are many studies about robust biased estimators in the literature to solve these problems simultaneously. The most commonly used of these estimators are robust Ridge estimators. Many studies are still carried out on the Ridge estimator, which depends on the biasing parameter. The performances of the previously proposed biased parameters were compared in the classical Ridge estimator. In this study, we have compared the performances of the biasing parameters for the robust Ridge GM estimators based on the simulation and real data studies.
\end{abstract}

\section{Keywords- Linear Regression Model, Multicollinearity, Outlier, Ridge Regression, Biasing Parameter}

\footnotetext{
*Bu çalıșma Dr. Öğr. Üyesi Y. Murat Bulut danıșmanlığında Melike Ișılar tarafından, Eskișehir Osmangazi Üniversitesi, Fen Bilimleri Enstitüsü, İstatistik Anabilim dalı, İstatistik Teorisi Bilim dalında tamamlanan yüksek lisans tezinin bir bölümünden üretilmiștir.

1İletişim: melikeisilar@gmail.com (https://orcid.org/0000-0001-6821-1064)

Eskişehir Osmangazi Üniversitesi, Fen Bilimleri Enstitüsü, 26040, Eskişehir, Türkiye

2*Sorumlu yazar iletișim: ymbulut@ogu.edu.tr (https://orcid.org/0000-0002-0545-7339)

İstatistik Bölümü, Eskişehir Osmangazi Üniversitesi, Fen-Edebiyat Fakültesi, 26040, Eskişehir, Türkiye
} 


\section{GİRIŞ}

Bağımsız değişkenler ile bağımlı değişkenler arasındaki ilişkiyi modellemek için istatistikte yaygın olarak kullanılan teknik regresyon analizidir. Lineer regresyon analizinde parametreleri tahmin etmek için en küçük kareler (EKK) tahmin edicisi kullanılmaktadır. Regresyon analizinin varsayımlarının sağlanması durumunda EKK tahmin edicisi lineer tahmin ediciler içinde en iyi yansız tahmin edicidir.

Uygulamada elde edilen verilerde genellikle regresyon analizinin varsayımları sağlanamamaktadır. Varsayımların bozulmasına neden olan problemler genellikle veri setinde aykırı değer bulunması ve bağımsız değişkenler arasında lineer bir ilişki olması durumlarıdır.

Veri setinde aykırı değer bulunması durumunda bu problemin çözümü için sıklıkla sağlam tahmin ediciler kullanılmaktadır. Regresyon analizinde aykırı değer probleminin çözümü için yaygın olarak Huber [1] tarafindan önerilen M tipi tahmin ediciler kullanılmaktadır. Bağımlı değişkende aykırı değer bulunması durumda etkin sonuçlar veren $\mathrm{M}$ tahmin edicisi (ME), bağımsız değişkende aykırı değer bulunması durumunda etkinliğini kaybetmektedir. Bu nedenle bağımsız değişkende de aykırı değer bulunması durumunda etkin sonuçlar elde etmek amacıyla Mallows [2] ve Handschin vd. [3] tarafindan farklı iki çalışma ile Genelleş̧irilmiş M tahmin edicisi (GME) önerilmiştir.

Çoklu lineer regresyon modelinde bağımsız değiş̧enler arasında şiddetli bir lineer ilişki bulunması durumu çoklu iç ilişki problemi olarak adlandırılmaktadır. Çoklu iç ilişki probleminde EKK tahmin edicisinin varyansı artmaktadır. Bu problemin çözümü için literatürde genellikle yanlı tahmin ediciler kullanılmaktadır. Yaygın olarak bilinen yanlı tahmin edici Hoerl ve Kennard [4] tarafından önerilen Ridge tahmin edicisidir (RE). $\mathrm{RE}, k$ yanlılık parametresine bağlı bir tahmin edicidir. $k$ parametresi RE' nin lineer bir fonksiyonu olarak yazılamamaktadır. $\mathrm{Bu}$ nedenle $k$ parametresinin tahmini için literatürde pek çok çalışma mevcuttur. $\mathrm{Bu}$ çalışmalardan bazıları: Theobald [5], Hoerl vd. [6], Lawless [7], Hocking vd. [8], Kibria [9], Khalaf ve Shukur [10], Alkhamisi vd. [11], Alkhamisi ve Shukur [12], Muniz ve Kibria [13], Al-Hassan [14], Muniz vd. [15], Dorugade [16], Karaibrahimoğlu vd. [17], Asar ve Genç [18] tarafindan yapılan çalışmalardır.

Uygulamada aykırı değer ve çoklu iç ilişki problemleri ile tek tek karşılaşılabileceği gibi sıklıkla bu problemler birlikte de görülmektedir. Bu nedenle problemlerin ortak çözümleri için sağlam Ridge tahmin edicileri önerilmiştir. Sağlam Ridge tahmin edicisi olarak Silvapulle [19] tarafindan Ridge M tahmin edicisi (RME) önerilmiştir. RME, ME' ye bağlı olduğu için bağımlı değişkende aykırı değer bulunması durumunda etkin sonuçlar verse de bağımsız değişkende aykırı değer bulunması durumunda etkinliğini kaybetmektedir. Bu problemin çözümü için ise Arslan ve Billor [20] tarafından çoklu iç ilişki ve hem bağımlı hem de bağımsız değişkende aykırı değer bulunması problemlerinin ortak çözümleri için Ridge GM tahmin edicisi (RGME) önerilmiştir.

Sağlam Ridge tahmin edicilerinin performansı da $k$, yanlılık parametresine bağlıdır. Literatürde önerilen $k$ parametresi tahmin edicilerinin performansları RE için karşılaştırılmıştır [21]. Sağlam Ridge tahmin edicileri ile ilgili yapılan çalışmalarda genellikle Hoerl ve Kennard [4] tarafindan önerilen $k$ parametresinin tahmin edicisi kullanılmıştır. Işılar [22] tezinde veri setinde hem bağımlı hem de bağımsız değişkende aykırı değer olması ve bağımsız değişkenler arasında yüksek lineer ilişki olması durumunda önerilen farklı $k$ tahmin edicilerine bağlı olarak RGME' nin performanslarını karşılaştırmıştır. Bu çalışmada da veri setinde aykırı değer bulunması durumunda önerilen $k$ parametrelerinin performansları RE, RME ve RGME tahmin edicileri için karşılaştııılmıştır. $\mathrm{Bu}$ amaçla ikinci bölümde regresyon analizinde kullanılan EKK, M, GM, RE, RME ve RGME anlatılmıştır. Üçüncü bölümde RE' de $k$ parametresi için önerilen tahmin ediciler verilmiştir. Dördüncü bölümde ise simülasyon çalışması ve gerçek veri örneğinin sonuçları verilmiştir. Beşinci bölümde ise simülasyon ve gerçek veriden elde edilen sonuçlar özetlenmiştir.

\section{LINEER REGRESYON ANALIZI VE PARAMETRE TAHMINI}

Çoklu lineer regresyon modeli,

$y=\boldsymbol{X} \beta+\varepsilon$

şeklindedir. Burada $\mathrm{y} ; n \times 1$ boyutlu bağımlı değişken vektörü, $\mathbf{X} ; n \times p$ boyutlu bağımsız değişsen matrisi, $\beta$; $p \times 1$ boyutlu parametre vektörü, $\varepsilon ; n \times 1$ boyutlu hata vektörüdür. Ayrıca hata terimleri $E(\varepsilon)=0$ ve $\operatorname{Cov}(\varepsilon)=$ $\sigma^{2} I^{\prime}$ dir.

Regresyon analizinde parametreleri tahmin etmek için sıklıkla Eşitlik (2)' de verilen EKK tahmin edicisi kullanılmaktadır. 


$$
\hat{\beta}=\left(\boldsymbol{X}^{\prime} \boldsymbol{X}\right)^{-1} \boldsymbol{X}^{\prime} \boldsymbol{y}
$$

EKK tahmin edicisine ait matris hata kareler ortalaması (MMSE) ve hata kareler ortalaması (MSE) denklemleri sırasıyla Eşitlik (3) ve Eşitlik (4)' te verildiği gibidir.

$$
\begin{aligned}
& \operatorname{MMSE}(\hat{\beta})=\sigma^{2}\left(\boldsymbol{X}^{\prime} \boldsymbol{X}\right)^{-1} \\
& \operatorname{MSE}(\hat{\beta})=\sigma^{2} \sum_{j=1}^{p} \frac{1}{\lambda_{j}}
\end{aligned}
$$

Burada $\lambda_{j}, \boldsymbol{X}^{\prime} \boldsymbol{X}$ matrisinin öz değerleridir.

Aykırı değer probleminin çözümü için Huber [1] tarafından önerilen ME' nin amaç fonksiyonu,

$$
\arg \min _{\beta} \rho\left(\frac{\varepsilon}{\sigma}\right)
$$

şeklindedir. ME' de kullanılacak olan $\rho$, amaç fonksiyonunun sağlaması gereken özellikler aşağıdaki gibidir:

- $\rho(\varepsilon) \geq 0$

- $\rho(0)=0$

- $\rho(\varepsilon)=\rho(-\varepsilon)$

- $0<\varepsilon_{i}<\varepsilon_{j}$ için $\rho\left(\varepsilon_{i}\right)<\rho\left(\varepsilon_{j}\right)$.

Bağımsız değişkende de aykırı değer bulunması durumunda etkin sonuçlar elde etmek amacıyla önerilen GM tahmin edicisinin genel olarak amaç fonksiyonu,

$$
\arg \min _{\beta} \sigma^{2} \rho\left(\frac{\varepsilon}{\sigma u^{\alpha}}\right) u^{\alpha+1}
$$

şeklindedir [23]. Burada $u$, bağımsız değişkenlere bağlı olarak hesaplanan gözlemlere verilen ağırlık vektörüdür. Mallows [3] GM tahmin edicisinin genel amaç fonksiyonunda $\alpha=0$ olması durumunda Mallows tipi GM tahmin edicisini, Handschin vd. [4] ise $\alpha=1$ olması durumunda Schweppe tipi GM tahmin edicisini önermişlerdir.

Çoklu iç ilişki problemi Farrar ve Glauber [24] tarafindan X matrisinin ortogonal olmaması olarak tanımlanmıştır. Bu tanımdan yola çıkarak Silvey [25] $\mathbf{X}$ matrisini ortogonalliğe yaklaştırmak amacıyla genel regresyon modelini Eşitlik (7)' de verilen kanonik formda tanımlamıştır.

$$
y=\boldsymbol{X} \beta+\varepsilon=\boldsymbol{X} \boldsymbol{Z} \boldsymbol{Z}^{\prime} \beta+\varepsilon=\boldsymbol{T} \alpha+\varepsilon
$$

Yapılan çalışmalarda genellikle $\boldsymbol{Z}$ matrisi $\boldsymbol{X}^{\prime} \boldsymbol{X}$ matrisinin özvektörlerinden oluşan matris olarak seçilse de herhangi bir ortogonal matris olarak önerilmiştir.

Çoklu iç ilişki probleminin çözümü için Hoerl ve Kennard [4] tarafindan önerilen RE' nin EKK tahmin edicisine göre lineer dönüşümü ile çözümü Eşitlik (8)' de verilmiştir:

$$
\hat{\alpha}(k)=\boldsymbol{Q}_{k}^{-1} \boldsymbol{Q} \hat{\alpha}
$$

Burada $k>0$, yanlılık parametresi olmak üzere $\boldsymbol{Q}=\boldsymbol{T}^{\prime} \boldsymbol{T}$ ve $\boldsymbol{Q}_{k}=\boldsymbol{T}^{\prime} \boldsymbol{T}+k \boldsymbol{I}$ ' dır. RE' nin MMSE ve MSE denklemleri sırasıyla Eşitlik (9) ve (10)' da verildiği gibidir:

$$
\begin{aligned}
& \operatorname{MMSE}(\hat{\alpha}(k))=\sigma^{2} \boldsymbol{Q}_{k}^{-1} \boldsymbol{Q} \boldsymbol{Q}_{k}^{-1}+k^{2} \boldsymbol{Q}_{k}^{-1} \alpha^{\prime} \alpha \boldsymbol{Q}_{k}^{-1} \\
& \operatorname{MSE}(\widehat{\alpha}(k))=\sigma^{2} \sum_{j=1}^{p} \frac{\lambda_{j}}{\left(\lambda_{j}+k\right)^{2}}+k^{2} \sum_{j=1}^{p} \frac{\alpha_{j}^{2}}{\left(\lambda_{j}+k\right)^{2}}
\end{aligned}
$$

Çoklu iç ilişki ve aykırı değer problemlerinin eşanlı çözümleri için Silvapulle [19] tarafından önerilen RME Eşitlik (11)' de verilmiştir:

$$
\hat{\alpha}\left(k_{M}\right)=\boldsymbol{Q}_{k_{M}}^{-1} \boldsymbol{Q} \hat{\alpha}_{M}
$$

Burada $k_{M}>0, \hat{\alpha}_{M}$ ile tahmin edilen yanlllı parametresidir. RME' nin MMSE ve MSE denklemleri sırasıyla Eşitlik (12) ve (13)' de verildiği gibi tanımlanmıştır:

$$
\operatorname{MMSE}\left(\hat{\alpha}\left(k_{M}\right)\right)=\boldsymbol{Q}_{k_{M}}^{-1} \boldsymbol{Q} \boldsymbol{\Omega} \boldsymbol{Q}_{k_{M}}^{-1}+k^{2} \boldsymbol{Q}_{k_{M}}^{-1} \alpha^{\prime} \alpha \boldsymbol{Q}_{k_{M}}^{-1}
$$




$$
\operatorname{MSE}\left(\hat{\alpha}\left(k_{M}\right)\right)=\sum_{j=1}^{p} \frac{\lambda_{j}^{2} \Omega_{j j}}{\left(\lambda_{j}+k\right)^{2}}+k^{2} \sum_{j=1}^{p} \frac{\alpha_{j}^{2}}{\left(\lambda_{j}+k\right)^{2}}
$$

Burada $\boldsymbol{\Omega}$, ME’ nin kovaryans matrisidir.

RME' nin bağımsız değişkende aykırı değer bulunması durumunda etkinliğini kaybetmesinden dolayı Arslan ve Billor [20] tarafindan Eşitlik (14)' te verilen RGME tahmin edicisi önerilmiştir:

$$
\hat{\alpha}\left(k_{G M}\right)=\boldsymbol{Q}_{k_{G M}}^{-1} \boldsymbol{Q} \hat{\alpha}_{G M}
$$

RGME' ne ait MMSE ve MSE denklemleri ise Eşitlik (15) ve (16)' da verildiği gibidir.

$$
\begin{aligned}
& \operatorname{MMSE}\left(\hat{\alpha}\left(k_{G M}\right)\right)=\boldsymbol{Q}_{k_{G M}}^{-1} \boldsymbol{Q} \boldsymbol{\Omega}^{\star} \boldsymbol{Q}_{k_{G M}}^{-1}+k^{2} \boldsymbol{Q}_{k_{G M}}^{-1} \alpha^{\prime} \alpha \boldsymbol{Q}_{k_{G M}}^{-1} \\
& \operatorname{MSE}\left(\hat{\alpha}\left(k_{G M}\right)\right)=\sum_{j=1}^{p} \frac{\lambda_{j} \Omega_{j j}^{\star}}{\left(\lambda_{j}+k\right)^{2}}+k^{2} \sum_{j=1}^{p} \frac{\alpha_{j}^{2}}{\left(\lambda_{j}+k\right)^{2}}
\end{aligned}
$$

Burada $\mathbf{\Omega}^{\star}$, GM tahmin edicisinin kovaryans matrisidir.

\section{YANLILIK PARAMETRESI İÇIN TAHMIN EDICCILER}

Bu bölümde RE' de $k$ parametresi için literatürde önerilmiş olan bazı tahmin ediciler verilmiştir.

Bu tahmin edicilerden $k_{1}$ ve $k_{2}$ tahmin edicileri Hoerl ve Kennard [4], $k_{3}$ tahmin edicisi Theobald [5] ve $k_{4}$ tahmin edici ise Hoerl vd. [6] tarafından önerilmiştir:

$$
\hat{k}_{1}=\frac{\widehat{\sigma}^{2}}{\hat{\alpha}^{\prime} \widehat{\alpha}}, \hat{k}_{2}=\frac{\widehat{\sigma}^{2}}{\hat{\alpha}_{\text {max }}^{2}}, \hat{k}_{3}=\frac{2 \widehat{\sigma}^{2}}{\hat{\alpha}^{\prime} \widehat{\alpha}}, \hat{k}_{4}=\frac{p \widehat{\sigma}^{2}}{\widehat{\alpha}^{\prime} \widehat{\alpha}}
$$

Daha sonra $k_{5}$ tahmin edicisi Lawless [7] ve $k_{6}$ tahmin edicisi ise Hocking vd. [8] tarafindan önerilmiştir:

$$
\hat{\mathrm{k}}_{5}=\frac{p \widehat{\sigma}^{2}}{\sum_{j=1}^{p} \lambda_{j} \hat{\alpha}_{j}^{2}}, \hat{k}_{6}=\hat{\sigma}^{2} \frac{\sum_{j=1}^{p} \lambda_{j} \widehat{\alpha}_{j}^{2}}{\left(\sum_{j=1}^{p} \lambda_{j} \widehat{\alpha}_{j}^{2}\right)^{2}}
$$

$k_{7}-k_{9}$ tahmin edicileri ise $m_{j}=\hat{\sigma}^{2} / \hat{\alpha}_{j}^{2}$ olmak üzere Kibria [9] tarafından önerilmiştir:

$$
\hat{\mathrm{k}}_{7}=\operatorname{mean}\left(m_{j}\right), \hat{k}_{8}=\operatorname{median}\left(m_{j}\right), \hat{k}_{9}=\frac{\widehat{\sigma}^{2}}{\left(\Pi_{j=1}^{p} \widehat{\alpha}_{j}^{2}\right)^{1 / p}}
$$

$k_{10}$ tahmin edicisi Khalaf ve Shukur [10] tarafindan tanımlanmıştır:

$$
\hat{\mathrm{k}}_{10}=\frac{\lambda_{\max } \hat{\sigma}^{2}}{(n-p-1) \hat{\sigma}^{2}+\lambda_{\max } \hat{\alpha}_{\max }^{2}}
$$

Daha sonra Alkhamisi vd. [11] çalışmasında $t_{j}=\frac{\lambda_{j} \widehat{\sigma}^{2}}{(n-p-1) \widehat{\sigma}^{2}+\lambda_{j} \widehat{\alpha}_{j}^{2}}$ olmak üzere $k_{11}-k_{13}$ tahmin edicilerini önermişlerdir:

$$
\hat{\mathrm{k}}_{11}=\max \left(t_{j}\right), \hat{k}_{12}=\operatorname{mean}\left(t_{j}\right), \hat{k}_{13}=\operatorname{median}\left(t_{j}\right)
$$

Alkhamisi ve Shukur [12] çalışmasında ise $k_{14}-k_{18}$ tahmin edicilerini geliştirmişlerdir:

$$
\begin{gathered}
\hat{k}_{14}=\frac{p \widehat{\sigma}^{2}}{\widehat{\alpha}^{\prime} \widehat{\alpha}}+\frac{1}{\lambda_{\max }}, \hat{k}_{15}=\frac{p \widehat{\sigma}^{2}}{\sum_{j=1}^{p} \lambda_{j} \widehat{\alpha}_{j}^{2}}+\frac{1}{\lambda_{\max }}, \hat{\mathrm{k}}_{16}=\max \left(\frac{\widehat{\sigma}^{2}}{\widehat{\alpha}_{j}^{2}}+\frac{1}{\lambda_{j}}\right) \\
\hat{\mathrm{k}}_{17}=\operatorname{mean}\left(\frac{\widehat{\sigma}^{2}}{\widehat{\alpha}_{j}^{2}}+\frac{1}{\lambda_{j}}\right), \hat{\mathrm{k}}_{18}=\operatorname{median}\left(\frac{\widehat{\sigma}^{2}}{\widehat{\alpha}_{j}^{2}}+\frac{1}{\lambda_{j}}\right)
\end{gathered}
$$


Ayrıca $k_{19}-k_{25}$ tahmin edicileri ise $\hat{\sigma}_{j}^{2}, j$. bağımsız değişkenin varyansı ve $f_{j}=\sqrt{\frac{\widehat{\sigma}_{j}^{2}}{\widehat{\alpha}_{j}^{2}}}$ olmak üzere Muniz ve Kibria [13] tarafindan önerilmiştir:

$$
\begin{aligned}
& \hat{\mathrm{k}}_{19}=\max \left(f_{j}\right), \hat{\mathrm{k}}_{20}=\max \left(\frac{1}{f_{j}}\right), \hat{\mathrm{k}}_{21}=\operatorname{median}\left(f_{j}\right), \hat{\mathrm{k}}_{22}=\operatorname{median}\left(\frac{1}{f_{j}}\right) \\
& \hat{\mathrm{k}}_{23}=\operatorname{geomean}\left(f_{i}\right), \hat{k}_{24}=\operatorname{geomean}\left(\frac{1}{f_{j}}\right), \hat{\mathrm{k}}_{25}=\left(\prod_{j=1}^{p} \frac{\lambda_{j} \widehat{\sigma}_{j}^{2}}{(n-p-1) \hat{\sigma}_{j}^{2}+\lambda_{j} \hat{\alpha}_{j}^{2}}\right)^{\frac{1}{p}}
\end{aligned}
$$

Al-Hassan [14] çalışmasında ise $k_{26}$ tahmin edicisini önermiştir:

$$
\hat{\mathrm{k}}_{26}=\hat{\sigma}^{2} \frac{\sum_{j=1}^{p}\left(\lambda_{j} \hat{\alpha}_{j}\right)^{2}}{\left(\sum_{j=1}^{p} \lambda_{j} \hat{\alpha}_{j}^{2}\right)^{2}}+\frac{1}{\lambda_{j}}
$$

$v_{j}=\frac{\lambda_{\max } \widehat{\sigma}^{2}}{(n-p-1) \widehat{\sigma}^{2}+\lambda_{\max } \widehat{\alpha}_{j}^{2}}$ olmak üzere Muniz vd. [15] $k_{27}-k_{38}$ tahmin edicilerini tanımlamışlardır:

$$
\begin{aligned}
& \hat{k}_{27}=\operatorname{geomean}\left(t_{j}\right), \hat{k}_{28}=\max \left(\frac{1}{\sqrt{m_{j}}}\right), \hat{k}_{29}=\max \left(\sqrt{m_{j}}\right), \hat{k}_{30}=\operatorname{geomean}\left(\frac{1}{\sqrt{m_{j}}}\right) \\
& \hat{k}_{31}=\operatorname{geomean}\left(\sqrt{m_{j}}\right), \hat{k}_{32}=\operatorname{median}\left(\frac{1}{\sqrt{m_{j}}}\right), \hat{k}_{33}=\operatorname{median}\left(\sqrt{m_{j}}\right), \hat{k}_{34}=\max \left(\frac{1}{\sqrt{v_{j}}}\right) \\
& \hat{k}_{35}=\max \left(\sqrt{v_{j}}\right), \hat{k}_{36}=\operatorname{median}\left(\frac{1}{\sqrt{v_{j}}}\right), \hat{k}_{37}=\operatorname{geomean}\left(\frac{1}{\sqrt{v_{j}}}\right), \hat{k}_{38}=\operatorname{geomean}\left(\sqrt{v_{j}}\right)
\end{aligned}
$$

Dorugade [16] çalışmasında ise $k_{39}-k_{42}$ tahmin edicilerini geliştirmiştir:

$$
\hat{k}_{39}=\operatorname{mean}\left(\frac{2 \widehat{\sigma}^{2}}{\lambda_{\max } \widehat{\alpha}_{j}^{2}}\right), \hat{k}_{40}=\operatorname{median}\left(\frac{2 \widehat{\sigma}^{2}}{\lambda_{\max } \widehat{\alpha}_{j}^{2}}\right), \hat{k}_{41}=\frac{2 \widehat{\sigma}^{2}}{\lambda_{\max }}\left(\prod_{j=1}^{p} \hat{\alpha}_{j}^{2}\right)^{\frac{1}{p}}, \hat{k}_{42}=\frac{2 p \widehat{\sigma}^{2}}{\lambda_{\max }} \sum_{j=1}^{p} \frac{1}{\widehat{\alpha}_{j}^{2}}
$$

$k_{43}-k_{46}$ tahmin edicileri ise Karaibrahimoğlu vd. [17] tarafından önerilmiştir:

$$
\hat{k}_{43}=\frac{p}{\sqrt{\lambda_{\max }}} \frac{\widehat{\sigma}^{2}}{\sum_{j=1}^{p} \hat{\alpha}_{j}^{2}}, \hat{k}_{44}=\frac{\sqrt{5} p}{\lambda_{\max }} \frac{\widehat{\sigma}^{2}}{\sum_{j=1}^{p} \widehat{\alpha}_{j}^{2}}, \hat{k}_{45}=\frac{2 p}{\sum_{j=1}^{p} \lambda_{j}^{1 / 4}} \frac{\widehat{\sigma}^{2}}{\sum_{j=1}^{p} \widehat{\alpha}_{j}^{2}}, \hat{k}_{46}=\frac{2 p}{\sqrt{\sum_{j=1}^{p} \lambda_{j}}} \frac{\widehat{\sigma}^{2}}{\sum_{j=1}^{p} \widehat{\alpha}_{j}^{2}}
$$

Daha sonra Asar ve Genç [18] çalışmasında $h_{j}=\sqrt{\frac{\hat{\sigma}^{2}}{\lambda_{j} \widehat{\alpha}_{j}^{2}}}$ olmak üzere $k_{47}-k_{54}$ tahmin edicilerini önermişlerdir:

$$
\begin{gathered}
\hat{k}_{47}=\text { mean }\left(h_{j}\right), \hat{k}_{48}=\operatorname{geomean}\left(h_{j}\right), \hat{k}_{49}=\operatorname{median}\left(h_{j}\right), \hat{k}_{50}=\max \left(h_{j}\right) \\
\hat{k}_{51}=\text { median }\left(\frac{1}{h_{j}}\right), \hat{k}_{52}=\text { mean }\left(\frac{1}{h_{j}}\right), \hat{k}_{53}=\operatorname{harmmean}\left(\frac{1}{h_{j}}\right), \hat{k}_{54}=\operatorname{harmmean}\left(h_{j}\right)
\end{gathered}
$$

$\mathrm{Bu}$ tahmin edicilerde mean, geomean, median ve harmmean sirasıly ortalama, geometrik ortalama, medyan ve harmonik ortalamayı ifade etmektedir. 


\section{SIMUÜLASYON CCALIȘMASI VE GERÇEK VERİ UYGULAMASI}

\section{A. Simülasyon Çalışması}

Simülasyon çalışmasında hem bağımlı hem de bağımsız değişkende aykırı değer ve çoklu iç ilişki bulunan veri setleri üretilmiştir. Bu amaçla McDonald ve Galarneau' nun [26] Eşitlik (17)' de verilen formülü kullanılarak ilişkili bağımsız değişkenler üretilmiştir.

$$
x_{i j}=\left(1-\rho^{2}\right)^{1 / 2} z_{i j}+\rho z_{i(p+1)}, \quad i=1,2, \ldots, n, j=1,2, \ldots, p
$$

Burada $\mathrm{p}$, bağımsız değişken sayısı, n, örneklem hacmi olmak üzere $\rho^{2}$ bağımsız değişkenler arasındaki korelasyon katsayısı, $\mathrm{z}_{\mathrm{ij}}$ ise $\mathrm{N}(0,1)$ dağılımından olan rassal sayılardır.

$\beta$ parameter vektörü, $\boldsymbol{X}^{\prime} \boldsymbol{X}$ matrisinin en büyük öz değerine karşılık gelen öz vektörü seçilerek $\beta^{\prime} \beta=1$ olacak şekilde seçilmiştir [27]. Aralarında yüksek lineer ilişki olan bağımsız değişkenler üretildikten sonra Eşitlik (1)' de verilen formül ile bağımlı değişken vektörü oluşturulmuştur. Bu çalışmada bağımsız değişkende de aykırı değer bulunması durumunda RME tahmin edicisinin etkinliğini kaybetmesinden dolayı RGME tahmin edicisi üzerinde durulmuştur. $\mathrm{Bu}$ nedenle simülasyon çalışmasında bağımlı değişken vektöründe \%5 aykırı değer bulunurken bağımsız değişkenlerde $\% 5$ ve $\% 10$ aykırı değer bulunması durumları ele alınmıştır. Hem bağımlı hem de bağımsız değişkende aykırı değer bulunması durumu ele alındığı için üretilen veri setlerinde a tane aykırı değer, bağımlı değişkende birinci gözlemden a. gözleme kadar, bağımsız değişkenlere ise (n-a+1). gözlemden n. gözleme kadar olan gözlemler için oluşturulmuştur. Bağımlı değişken vektöründeki \%5 gözlem N(10,1) dağılımından rassal üretilen sayılar ile değiştirilmiştir. Bağımsız değişken matrisindeki örneklem hacminin \%5 ve \%10'u kadar olan sondaki satırlar ise yine benzer şekilde $\mathrm{N}(10,1)$ dağılımından rassal olarak üretilen sayılar ile değiştirilmiştir.

Simülasyon çalışmaları için örnek hacmi 30, 50 ve 70, bağımsız değişken sayısı 4 ve 6 , korelasyon değeri 0,90, 0,95 ve 0,99, bağımsız değişkendeki aykırı değer oranları ise \%5 ve \%10 olarak seçilmiştir. Lineer regresyon modeli ise sabit terimsiz olarak kurulmuştur. Simülasyonlar 5000 tekrar ile çalıştırılmıştır. Gerçek veri uygulaması ve simülasyon çalışmaları R programı kullanılarak yapılmıştır [28]. Tahmin edicilerin Eşitlik (18)' de verilen denklem kullanılarak MSE değerleri hesaplanmıştır:

$$
\operatorname{MSE}\left(\hat{\alpha}^{\star}\right)=\frac{1}{5000} \sum_{i=1}^{5000}\left(\hat{\alpha}_{i}^{\star}-\alpha\right)^{\prime}\left(\hat{\alpha}_{i}^{\star}-\alpha\right)
$$

Burada $\hat{\alpha}^{\star}, \alpha^{\prime}$ nın herhangi bir tahmin edicisini göstermektedir. Simülasyon çalışması sonucunda tahmin edicilerin MSE değerlerine ait sonuçlar ise Tablo 1-4' te verilmiştir. 
Tablo 1. $\mathrm{p}=4$ ve $\% 5$ aykırı değer bulunması durumunda MSE değerleri

\begin{tabular}{|c|c|c|c|c|c|c|c|c|c|}
\hline \multirow[t]{2}{*}{ n } & \multicolumn{3}{|c|}{30} & \multicolumn{3}{|c|}{50} & \multicolumn{3}{|c|}{70} \\
\hline & 0,90 & 0,95 & 0,99 & 0,90 & 0,95 & 0,99 & 0,90 & 0,95 & 0,99 \\
\hline$\alpha$ & 7,1194 & 13,2705 & 62,8334 & 3,6846 & 7,0236 & 42,3089 & 3,0381 & 5,0692 & 27,5966 \\
\hline $\boldsymbol{\alpha}_{M}$ & 4,5433 & 8,7354 & 48,2042 & 2,9147 & 3,4999 & 31,7434 & 2,1452 & 3,2538 & 20,9420 \\
\hline $\boldsymbol{\alpha}_{\mathrm{GM}}$ & 2,1347 & 3,5539 & 13,7652 & 11,3489 & 1,7861 & 6,8050 & 1,1595 & 1,5816 & 4,9936 \\
\hline$k_{1}$ & 1,8597 & 3,0101 & 11,3489 & 1,2290 & 1,5902 & 5,6711 & 1,0990 & 1,4533 & 4,3900 \\
\hline$k_{2}$ & 1,5015 & 2,2596 & 7,9760 & 1,0956 & 1,3468 & 4,0918 & 1,0100 & 1,2769 & 3,4600 \\
\hline$k_{3}$ & 1,6794 & 2,6484 & 9,8598 & 1,1654 & 1,4494 & 4,9455 & 1,0573 & 1,3616 & 3,9793 \\
\hline$k_{4}$ & 1,4418 & 2,1794 & 7,9773 & 1,0722 & 1,2580 & 4,0220 & 0,9923 & 1,2268 & 3,4051 \\
\hline$k_{5}$ & 2,1159 & 3,5290 & 13,3525 & 1,3098 & 1,7818 & 6,7259 & 1,1490 & 1,5693 & 4,9472 \\
\hline$k_{6}$ & 1,4401 & 1,8398 & 3,2181 & 1,1606 & 1,3463 & 2,6176 & 1,0555 & 1,3167 & 2,5249 \\
\hline$k_{7}$ & 0,9628 & 1,2785 & 3,2913 & 0,8437 & 0,8933 & 2,1377 & 0,8077 & 0,8847 & 2,0652 \\
\hline$k_{8}$ & 1,2115 & 1,7236 & 4,9825 & 0,9545 & 1,0968 & 2,9057 & 0,8965 & 1,0783 & 2,7444 \\
\hline$k_{9}$ & 1,5453 & 2,3063 & 8,0129 & 1,1363 & 1,3873 & 4,1453 & 1,0416 & 1,3155 & 3,4934 \\
\hline$k_{10}$ & 1,4415 & 1,8414 & 3,0573 & 1,1654 & 1,3564 & 2,6200 & 1,0587 & 1,3227 & 2,5382 \\
\hline$k_{11}$ & 1,7740 & 2,6421 & 6,2143 & 1,2468 & 1,5996 & 4,5075 & 1,1099 & 1,4722 & 3,9358 \\
\hline$k_{12}$ & 1,9684 & 3,2418 & 11,7828 & 1,2778 & 1,7212 & 6,3204 & 1,1320 & 1,5360 & 4,7248 \\
\hline$k_{13}$ & 1,3523 & 1,6050 & 2,4929 & 1,1022 & 1,2977 & 2,2648 & 1,0293 & 1,2352 & 2,1595 \\
\hline$k_{14}$ & 1,0651 & 1,5089 & 5,3466 & 0,8281 & 0,9832 & 3,2038 & 0,7900 & 0,9187 & 2,2577 \\
\hline$k_{15}$ & 1,1280 & 1,6465 & 6,8974 & 0,9839 & 1,2355 & 4,0300 & 0,8836 & 1,0097 & 3,0914 \\
\hline$k_{16}$ & $\mathbf{0 , 8 2 5 1}$ & 0,9860 & 1,4678 & 0,7972 & 0,8068 & 1,3204 & 0,7886 & 0,7881 & 1,4749 \\
\hline$k_{17}$ & 0,9532 & 1,2255 & 2,1444 & 0,8822 & 0,8953 & 1,8456 & 0,8572 & 0,8714 & 1,7284 \\
\hline$k_{18}$ & 1,1946 & 1,6297 & 2,6952 & 0,9508 & 1,0797 & 2,4464 & 0,8952 & 1,0721 & 2,2267 \\
\hline$k_{19}$ & 0,8529 & 0,9968 & 1,5373 & 0,8484 & 0,8804 & 1,4199 & 0,8248 & 0,8575 & 1,3709 \\
\hline$k_{20}$ & 1,8469 & 2,5592 & 3,6582 & 1,2504 & 2,5545 & 2,8324 & 1,1230 & 1,4774 & 2,2768 \\
\hline$k_{21}$ & 1,1333 & 1,4222 & 2,8407 & 0,9705 & 1,1447 & 2,1050 & 0,9272 & 1,0511 & 2,0548 \\
\hline$k_{22}$ & 1,9622 & 2,9477 & 5,8537 & 1,2752 & 1,6382 & 3,9256 & 1,1354 & 1,5138 & 3,8855 \\
\hline$k_{23}$ & 1,0943 & 1,3728 & 2,8212 & 0,9539 & 1,1042 & 2,0064 & 0,9271 & 1,0204 & 1,9969 \\
\hline$k_{24}$ & 1,9869 & 3,0123 & 6,2080 & 1,2822 & 1,6661 & 4,1083 & 1,1382 & 1,5247 & 3,9748 \\
\hline$k_{25}$ & 1,8430 & 2,9476 & 9,9846 & 1,2524 & 1,6583 & 5,8287 & 1,1159 & 1,4976 & 4,4724 \\
\hline$k_{26}$ & 1,5012 & 2,2586 & 7,9607 & 1,0955 & 1,3465 & 4,0879 & 1,0100 & 1,2769 & 3,4591 \\
\hline$k_{27}$ & 1,9275 & 3,1250 & 11,0763 & 1,2687 & 1,6926 & 6,0923 & 1,1261 & 1,5206 & 4,6276 \\
\hline$k_{28}$ & 1,6216 & 1,9949 & 2,1763 & 1,1967 & 1,3948 & 2,0838 & 1,0934 & 1,3790 & 2,0211 \\
\hline$k_{29}$ & 1,0574 & 1,3469 & 2,6216 & 0,9089 & 0,9697 & 1,9920 & 0,8807 & 0,9516 & 1,8548 \\
\hline$k_{30}$ & 1,8466 & 2,5779 & 3,9914 & 1,2542 & 1,5667 & 3,0523 & 1,1246 & 1,4701 & 2,9501 \\
\hline$k_{31}$ & 1,4005 & 1,9203 & 4,6601 & 1,0713 & 1,2203 & 2,8791 & 0,9963 & 1,2201 & 2,8465 \\
\hline$k_{32}$ & 1,7998 & 2,4748 & 3,6924 & 1,2408 & 1,5205 & 2,9908 & 1,1184 & 1,4476 & 2,8193 \\
\hline$k_{33}$ & 1,4432 & 1,9822 & 4,6536 & 1,0849 & 1,2609 & 2,9364 & 1,0032 & 1,2470 & 2,9132 \\
\hline$k_{34}$ & 1,6173 & 1,9886 & 2,1724 & 1,1942 & 1,3894 & 2,0061 & 1,0923 & 1,3762 & 1,9440 \\
\hline$k_{35}$ & 1,1896 & 1,4856 & 2,7877 & 1,0217 & 1,1773 & 2,1605 & 0,9903 & 1,1135 & 2,0916 \\
\hline$k_{36}$ & 1,7887 & 2,4528 & 3,6560 & 1,2350 & 1,5073 & 2,9203 & 1,1156 & 1,4413 & 2,9029 \\
\hline$k_{37}$ & 1,8104 & 2,5005 & 3,8125 & 1,2400 & 1,5281 & 2,8837 & 1,1176 & 1,4521 & 2,8507 \\
\hline$k_{38}$ & 1,4737 & 2,0153 & 4,8002 & 1,1192 & 1,2934 & 3,0204 & 1,0318 & 1,2757 & 2,9618 \\
\hline$k_{39}$ & 2,0164 & 3,3752 & 13,0538 & 1,2726 & 1,7017 & 6,4318 & 1,1278 & 1,5253 & 4,8278 \\
\hline$k_{40}$ & 2,1111 & 3,5316 & 13,6078 & 1,3044 & 1,7778 & 6,7690 & 1,1479 & 1,5691 & 4,9475 \\
\hline$k_{41}$ & 2,1147 & 3,5335 & 13,6697 & 1,3079 & 1,7795 & 6,7686 & 1,1484 & 1,5693 & 4,9545 \\
\hline$k_{42}$ & 1,7266 & 2,8174 & 10,5867 & 1,1734 & 1,4870 & 5,4540 & 1,0656 & 1,4138 & 4,3947 \\
\hline$k_{43}$ & 2,0815 & 3,4646 & 13,3427 & 1,2992 & 1,7567 & 6,6221 & 1,1443 & 1,5591 & 4,9000 \\
\hline$k_{44}$ & 2,1213 & 3,5470 & 13,7319 & 1,3102 & 1,7840 & 6,7914 & 1,1492 & 1,5709 & 4,9602 \\
\hline$k_{45}$ & 1,9061 & 3,0819 & 11,4703 & 1,2486 & 1,6261 & 5,7709 & 1,1158 & 1,4875 & 4,5127 \\
\hline$k_{46}$ & 2,0421 & 3,3829 & 12,9661 & 1,2881 & 1,7293 & 6,4550 & 1,1393 & 1,5471 & 4,8394 \\
\hline$k_{47}$ & 1,6172 & 2,2651 & 4,9919 & 1,1643 & 1,3762 & 3,1995 & 1,0662 & 1,3511 & 3,0028 \\
\hline$k_{48}$ & 1,8645 & 2,8004 & 7,1424 & 1,2476 & 1,5845 & 4,3913 & 1,1196 & 1,4825 & 4,0746 \\
\hline$k_{49}$ & 1,7744 & 2,5769 & 6,2686 & 1,2144 & 1,4959 & 3,8345 & 1,1011 & 1,4345 & 3,7487 \\
\hline$k_{50}$ & 1,3502 & 1,7288 & 3,1311 & 1,0649 & 1,3577 & 2,4250 & 1,0002 & 1,1996 & 2,3224 \\
\hline$k_{51}$ & 1,4478 & 1,7645 & 2,2241 & 1,1290 & 1,2647 & 2,0764 & 1,0448 & 1,2527 & 1,9975 \\
\hline$k_{52}$ & 0,9793 & 1,0286 & 1,2266 & 0,8529 & 0,8735 & 1,2064 & 0,8434 & 0,8591 & 1,1919 \\
\hline$k_{53}$ & 2,0272 & 3,2478 & 9,9182 & 1,2927 & 1,7234 & 5,7457 & 1,1420 & 1,5477 & 4,6524 \\
\hline$k_{54}$ & 1,6337 & 2,2068 & 4,0883 & 1,1795 & 1,4099 & 2,8572 & 1,0775 & 1,3450 & 2,6992 \\
\hline
\end{tabular}


Tablo 2. $p=4$ ve $\% 10$ aykırı değer bulunması durumunda MSE değerleri

\begin{tabular}{|c|c|c|c|c|c|c|c|c|c|}
\hline \multirow[t]{2}{*}{ n } & \multicolumn{3}{|c|}{30} & \multicolumn{3}{|c|}{50} & \multicolumn{3}{|c|}{70} \\
\hline & 0,90 & 0,95 & 0,99 & 0,90 & 0,95 & 0,99 & 0,90 & 0,95 & 0,99 \\
\hline $\boldsymbol{\alpha}$ & 6,4686 & 10,7607 & 44,6362 & 3,1362 & 4,8158 & 18,7822 & 2,6577 & 3,6993 & 12,6485 \\
\hline $\boldsymbol{\alpha}_{M}$ & 4,1172 & 7,3628 & 38,3169 & 2,4361 & 4,0766 & 14,1181 & 2,0376 & 3,0761 & 8,2952 \\
\hline$\alpha_{G M}$ & 2,3258 & 3,6835 & 15,9829 & 1,3652 & 2,0260 & 6,7367 & 1,1811 & 1,6448 & 5,6619 \\
\hline$k_{1}$ & 2,0464 & 3,1503 & 13,7358 & 1,2788 & 1,8394 & 6,0779 & 1,1256 & 1,5303 & 5,2676 \\
\hline$k_{2}$ & 1,6573 & 2,4338 & 10,2059 & 1,1418 & 1,5611 & 4,7470 & 1,0290 & 1,3441 & 4,4067 \\
\hline$k_{3}$ & 1,8574 & 2,8006 & 12,2875 & 1,2122 & 1,7005 & 5,6024 & 1,0806 & 1,4394 & 4,9509 \\
\hline$k_{4}$ & 1,6075 & 2,3456 & 10,3765 & 1,1148 & 1,5032 & 4,9214 & 1,0114 & 1,3026 & 4,4572 \\
\hline$k_{5}$ & 2,3130 & 3,6572 & 15,5212 & 1,3644 & 2,0241 & 6,7207 & 1,1806 & 1,6439 & 5,6541 \\
\hline$k_{6}$ & 1,5589 & 1,8529 & 4,4131 & 1,1875 & 1,5492 & 3,5555 & 1,0792 & 1,3699 & 3,2049 \\
\hline$k_{7}$ & 1,0949 & 1,3817 & 4,4235 & 0,8924 & 1,0535 & 2,8945 & 0,7930 & 0,9369 & 2,7161 \\
\hline$k_{8}$ & 1,3623 & 1,8080 & 6,5397 & 1,0019 & 1,3216 & 3,8227 & 0,9101 & 1,1503 & 3,6756 \\
\hline$k_{9}$ & 1,7015 & 2,4669 & 10,2422 & 1,1692 & 1,5843 & 4,7823 & 1,0608 & 1,3720 & 4,4396 \\
\hline$k_{10}$ & 1,5540 & 1,8417 & 4,0604 & 1,1907 & 1,5548 & 3,5158 & 1,0818 & 1,3747 & 3,2899 \\
\hline$k_{11}$ & 1,9138 & 2,6352 & 7,5338 & 1,2895 & 1,8228 & 5,1263 & 1,1399 & 1,5377 & 4,7685 \\
\hline$k_{12}$ & 2,1620 & 3,3485 & 13,5230 & 1,3291 & 1,9454 & 6,2559 & 1,1626 & 1,6051 & 5,4209 \\
\hline$k_{13}$ & 1,5167 & 1,7743 & 3,6086 & 1,1691 & 1,4726 & 3,1387 & 1,0682 & 1,3297 & 3,0633 \\
\hline$k_{14}$ & 1,1907 & 1,6298 & 5,7900 & 0,8700 & 1,0262 & 2,4645 & 0,7934 & 0,8985 & 2,0557 \\
\hline$k_{15}$ & 1,2148 & 1,6780 & 7,4798 & 0,8915 & 1,0778 & 3,2786 & 0,7998 & 0,9472 & 2,6609 \\
\hline$k_{16}$ & 0,9327 & 1,0576 & 2,2547 & 0,8219 & 0,9109 & 2,0036 & 0,7360 & 0,8069 & 1,9823 \\
\hline$k_{17}$ & 1,0860 & 1,3353 & 3,3725 & 0,8910 & 1,0472 & 2,6974 & 0,7926 & 0,9343 & 2,6403 \\
\hline$k_{18}$ & 1,3478 & 1,7322 & 4,3515 & 0,9993 & 1,3104 & 3,5000 & 0,9090 & 1,1458 & 3,2593 \\
\hline$k_{19}$ & 0,9777 & 1,0446 & 2,1288 & 0,8301 & 0,9071 & 1,7144 & 0,7759 & 0,8446 & 1,6003 \\
\hline$k_{20}$ & 2,0879 & 2,8019 & 5,6425 & 1,3273 & 1,8767 & 4,5499 & 1,1630 & 1,5771 & 4,5059 \\
\hline$k_{21}$ & 1,2670 & 1,4672 & 3,9703 & 0,9749 & 1,1755 & 2,6267 & 0,9193 & 1,0858 & 2,4889 \\
\hline$k_{22}$ & 2,1933 & 3,1838 & 8,4494 & 1,3424 & 1,9357 & 5,4504 & 1,1704 & 1,6037 & 5,0188 \\
\hline$k_{23}$ & 1,2281 & 1,4376 & 3,9819 & 0,9586 & 1,1293 & 2,6021 & 0,9052 & 1,0544 & 2,3200 \\
\hline$k_{24}$ & 2,2121 & 3,2293 & 8,9431 & 1,3464 & 1,9522 & 5,5518 & 1,1727 & 1,6112 & 5,0819 \\
\hline$k_{25}$ & 2,0116 & 3,0024 & 11,3809 & 1,2915 & 1,8569 & 5,7542 & 1,1420 & 1,5574 & 5,1238 \\
\hline$k_{26}$ & 1,6571 & 2,4332 & 10,1949 & 1,1417 & 1,5610 & 4,7460 & 1,0290 & 1,3441 & 4,4063 \\
\hline$k_{27}$ & 2,1112 & 3,2237 & 12,7824 & 1,3186 & 1,9196 & 6,1336 & 1,1561 & 1,5894 & 5,3332 \\
\hline$k_{28}$ & 1,8545 & 2,1949 & 3,3306 & 1,2683 & 1,6791 & 3,1258 & 1,1336 & 1,4781 & 3,0096 \\
\hline$k_{29}$ & 1,2275 & 1,4808 & 3,7795 & 0,9687 & 1,1549 & 2,8026 & 0,8893 & 1,0540 & 2,7912 \\
\hline$k_{30}$ & 2,0739 & 2,7773 & 6,0596 & 1,3151 & 1,8382 & 4,3719 & 1,1584 & 1,5577 & 4,0776 \\
\hline$k_{31}$ & 1,5852 & 2,0896 & 6,5258 & 1,1344 & 1,4784 & 4,0104 & 1,0330 & 1,3113 & 3,9057 \\
\hline$k_{32}$ & 2,0346 & 2,6970 & 5,6115 & 1,3048 & 1,7994 & 4,2187 & 1,1527 & 1,5392 & 3,9606 \\
\hline$k_{33}$ & 1,6256 & 2,1261 & 6,4918 & 1,1464 & 1,5230 & 4,0497 & 1,0422 & 1,3360 & 3,9713 \\
\hline$k_{34}$ & 1,8514 & 2,1902 & 3,3266 & 1,2671 & 1,6766 & 3,1214 & 1,1329 & 1,4764 & 2,9951 \\
\hline$k_{35}$ & 1,3472 & 1,6064 & 3,9894 & 1,0504 & 1,2684 & 2,9820 & 0,9776 & 1,1694 & 2,7393 \\
\hline$k_{36}$ & 2,0259 & 2,6806 & 5,5735 & 1,3021 & 1,7934 & 4,1988 & 1,1510 & 1,5354 & 3,9452 \\
\hline$k_{37}$ & 2,0448 & 2,7202 & 5,8231 & 1,3077 & 1,8156 & 4,2735 & 1,1539 & 1,5461 & 3,9999 \\
\hline$k_{38}$ & 1,6545 & 2,1724 & 6,7104 & 1,1678 & 1,5367 & 4,1202 & 1,0603 & 1,3554 & 4,0132 \\
\hline$k_{39}$ & 2,2203 & 3,5584 & 15,1391 & 1,3447 & 1,9677 & 6,5523 & 1,1685 & 1,6158 & 5,5676 \\
\hline$k_{40}$ & 2,3147 & 3,6678 & 15,8695 & 1,3626 & 2,0206 & 6,7243 & 1,1800 & 1,6425 & 5,6583 \\
\hline$k_{41}$ & 2,3169 & 3,6703 & 15,9017 & 1,3639 & 2,0230 & 6,7264 & 1,1805 & 1,6437 & 5,6584 \\
\hline$k_{42}$ & 1,9850 & 3,0900 & 12,9659 & 1,2759 & 1,8120 & 6,0292 & 1,1180 & 1,5329 & 5,2407 \\
\hline$k_{43}$ & 2,2874 & 3,6089 & 15,6601 & 1,3567 & 2,0074 & 6,6686 & 1,1766 & 1,6354 & 5,6297 \\
\hline$k_{44}$ & 2,3233 & 3,6787 & 15,9620 & 1,3648 & 2,0251 & 6,7333 & 1,1809 & 1,6444 & 5,6606 \\
\hline$k_{45}$ & 2,1070 & 3,2451 & 14,0023 & 1,3066 & 1,8930 & 6,2324 & 1,1468 & 1,5706 & 5,3906 \\
\hline$k_{46}$ & 2,2520 & 3,5401 & 15,3656 & 1,3486 & 1,9895 & 6,6038 & 1,1723 & 1,6264 & 5,5985 \\
\hline$k_{47}$ & 1,8354 & 2,5057 & 7,5096 & 1,2392 & 1,6680 & 4,6588 & 1,1102 & 1,4598 & 4,5180 \\
\hline$k_{48}$ & 2,0771 & 3,0167 & 9,9419 & 1,3150 & 1,8738 & 5,6290 & 1,1559 & 1,5753 & 5,1579 \\
\hline$k_{49}$ & 1,9867 & 2,8196 & 9,0761 & 1,2834 & 1,7988 & 5,2682 & 1,1385 & 1,5325 & 4,9582 \\
\hline$k_{50}$ & 1,5586 & 1,9449 & 5,0791 & 1,1431 & 1,4405 & 3,6049 & 1,0421 & 1,3113 & 3,2143 \\
\hline$k_{51}$ & 1,6475 & 1,8934 & 3,0159 & 1,1837 & 1,4826 & 2,4951 & 1,0781 & 1,3257 & 2,3290 \\
\hline$k_{52}$ & 1,1373 & 1,1404 & 1,6952 & 0,9014 & 0,9548 & 1,3023 & 0,8566 & 0,9110 & 1,2446 \\
\hline$k_{53}$ & 2,2324 & 3,4053 & 12,4620 & 1,3520 & 1,9850 & 6,3270 & 1,1750 & 1,6273 & 5,4901 \\
\hline$k_{54}$ & 1,8363 & 2,3357 & 5,3706 & 1,2324 & 1,6468 & 3,5797 & 1,1097 & 1,4209 & 3,4593 \\
\hline
\end{tabular}


Tablo 3. $p=6$ ve $\% 5$ aykırı değer bulunması durumunda MSE değerleri

\begin{tabular}{|c|c|c|c|c|c|c|c|c|c|}
\hline \multirow[t]{2}{*}{$\mathbf{n}$} & \multicolumn{3}{|c|}{30} & \multicolumn{3}{|c|}{50} & \multicolumn{3}{|c|}{70} \\
\hline & 0,90 & 0,95 & 0,99 & 0,90 & 0,95 & 0,99 & 0,90 & 0,95 & 0,99 \\
\hline$\alpha$ & 14,7481 & 28,7859 & 137,4686 & 7,4739 & 14,9097 & 82,1293 & 5,5992 & 9,9881 & 60,9919 \\
\hline $\boldsymbol{\alpha}_{M}$ & 11,0361 & 23,0871 & 111,2088 & 5,1496 & 8,6513 & 64,5336 & 4,4939 & 8,5927 & 49,9282 \\
\hline $\boldsymbol{\alpha}_{\mathrm{GM}}$ & 6,3140 & 9,6131 & 32,2741 & 4,5925 & 5,5989 & 13,6871 & 4,1612 & 4,8390 & 10,7460 \\
\hline$k_{1}$ & 5,8568 & 8,6607 & 28,0761 & 4,4653 & 5,3061 & 12,1441 & 4,0816 & 4,6610 & 9,9258 \\
\hline$k_{2}$ & 4,8753 & 6,8630 & 20,0016 & 3,9970 & 4,5440 & 9,3693 & 3,7302 & 4,1335 & 8,0547 \\
\hline$k_{3}$ & 5,5237 & 7,9811 & 25,1969 & 4,3629 & 5,0862 & 11,0671 & 4,0149 & 4,5199 & 9,3125 \\
\hline$k_{4}$ & 4,7452 & 6,4242 & 18,7439 & 4,0928 & 4,5559 & 8,6477 & 3,8277 & 4,1540 & 7,7979 \\
\hline$k_{5}$ & 6,2886 & 9,5014 & 30,9939 & 4,5905 & 5,5924 & 13,5807 & 4,1603 & 4,8356 & 10,7248 \\
\hline$k_{6}$ & 4,7039 & 5,4879 & 8,1856 & 4,3116 & 4,7859 & 6,6113 & 3,9983 & 4,3818 & 6,5509 \\
\hline$k_{7}$ & 3,2595 & 3,9800 & 7,3823 & 3,1928 & 3,4283 & 4,9122 & 3,1158 & 3,2839 & 4,7044 \\
\hline$k_{8}$ & 4,1996 & 5,3279 & 12,4383 & 3,8314 & 4,2044 & 6,8172 & 3,6061 & 3,8811 & 6,6672 \\
\hline$k_{9}$ & 4,0006 & 5,0407 & 11,9327 & 3,7657 & 4,0460 & 6,5201 & 3,5710 & 3,7693 & 6,2102 \\
\hline$k_{10}$ & 4,9326 & 6,9197 & 20,0499 & 4,0972 & 4,6239 & 9,4241 & 3,8144 & 4,1954 & 8,1040 \\
\hline$k_{11}$ & 4,6764 & 5,4527 & 7,7108 & 4,3153 & 4,7937 & 6,4618 & 4,0012 & 4,3873 & 6,3424 \\
\hline$k_{12}$ & 5,5471 & 7,4989 & 15,5233 & 4,4879 & 5,3196 & 10,3673 & 4,1043 & 4,6903 & 9,2341 \\
\hline$k_{13}$ & 5,9469 & 8,8717 & 28,9214 & 4,5289 & 5,4793 & 13,0944 & 4,1304 & 4,7786 & 10,3754 \\
\hline$k_{14}$ & 4,2213 & 5,6490 & 16,1727 & 3,7934 & 4,3196 & 8,8405 & 3,5279 & 3,8161 & 6,9916 \\
\hline$k_{15}$ & 4,3935 & 6,1407 & 19,6593 & 3,8860 & 4,4356 & 9,9876 & 3,5954 & 4,0271 & 8,4224 \\
\hline$k_{16}$ & 2,7633 & 3,2529 & 4,2335 & 2,7406 & 2,9670 & 3,6889 & 2,7190 & 2,8943 & 3,6559 \\
\hline$k_{17}$ & 3,2481 & 3,9096 & 5,5359 & 3,1913 & 3,4203 & 4,4351 & 3,1152 & 3,2810 & 4,4046 \\
\hline$k_{18}$ & 4,1591 & 5,1175 & 6,8273 & 3,8249 & 4,1739 & 5,5858 & 3,6041 & 3,8707 & 5,5801 \\
\hline$k_{19}$ & 3,4416 & 3,7475 & 4,8743 & 3,4154 & 3,5470 & 4,0722 & 3,3932 & 3,4526 & 4,0509 \\
\hline$k_{20}$ & 5,5365 & 6,8212 & 8,1939 & 4,4656 & 5,1263 & 6,8726 & 4,1137 & 4,6634 & 6,8052 \\
\hline$k_{21}$ & 4,1241 & 4,8687 & 8,0909 & 3,9066 & 4,1620 & 5,4574 & 3,6927 & 3,8858 & 5,3236 \\
\hline$k_{22}$ & 5,9339 & 8,0482 & 12,8606 & 4,5336 & 5,3486 & 8,7026 & 4,1409 & 4,7488 & 8,6027 \\
\hline$k_{23}$ & 4,0059 & 4,7171 & 7,7846 & 3,8618 & 4,0669 & 5,3072 & 3,6669 & 3,8162 & 5,2885 \\
\hline$k_{24}$ & 5,9972 & 8,2308 & 13,6304 & 4,5446 & 5,3978 & 9,0508 & 4,1444 & 4,7671 & 9,0441 \\
\hline$k_{25}$ & 5,7614 & 8,3850 & 25,0496 & 4,4988 & 5,4023 & 12,4175 & 4,1128 & 4,7369 & 10,0953 \\
\hline$k_{26}$ & 4,8748 & 6,8612 & 19,9692 & 3,9969 & 4,5437 & 9,3638 & 3,7302 & 4,1335 & 8,0535 \\
\hline$k_{27}$ & 5,8834 & 8,6471 & 26,6933 & 4,5187 & 5,4436 & 12,6913 & 4,1240 & 4,7605 & 10,2559 \\
\hline$k_{28}$ & 5,0536 & 5,7366 & 5,9838 & 4,3574 & 4,8088 & 5,7489 & 4,0605 & 4,4911 & 5,7856 \\
\hline$k_{29}$ & 3,6448 & 4,2410 & 6,3603 & 3,6334 & 3,7818 & 4,8305 & 3,5182 & 3,6130 & 4,8168 \\
\hline$k_{30}$ & 5,7184 & 7,3341 & 9,7424 & 4,4975 & 5,2222 & 7,3098 & 4,1241 & 4,6864 & 7,1389 \\
\hline$k_{31}$ & 4,5674 & 5,6851 & 10,8336 & 4,0832 & 4,4516 & 6,6475 & 3,8477 & 4,1446 & 6,3034 \\
\hline$k_{32}$ & 5,6087 & 7,0772 & 9,1388 & 4,4769 & 5,1398 & 6,9595 & 4,1166 & 4,6502 & 6,8010 \\
\hline$k_{33}$ & 4,7014 & 5,8875 & 11,2287 & 4,1233 & 4,5552 & 6,8604 & 3,8691 & 4,2111 & 6,5908 \\
\hline$k_{34}$ & 5,0489 & 5,7305 & 5,9813 & 4,3545 & 4,8030 & 5,9433 & 4,0592 & 4,4879 & 6,8995 \\
\hline$k_{35}$ & 3,9594 & 4,5165 & 6,6794 & 3,9351 & 4,0973 & 5,1399 & 3,7559 & 3,8888 & 5,0309 \\
\hline$k_{36}$ & 5,5902 & 7,0447 & 9,0989 & 4,4678 & 5,1207 & 7,0146 & 4,1124 & 4,6411 & 6,9706 \\
\hline$k_{37}$ & 5,6374 & 7,1647 & 9,4236 & 4,4719 & 5,1530 & 7,0464 & 4,1131 & 4,6552 & 6,8379 \\
\hline$k_{38}$ & 4,7169 & 5,8651 & 11,0819 & 4,1759 & 4,5855 & 6,8529 & 3,9153 & 4,2438 & 6,5200 \\
\hline$k_{39}$ & 5,9813 & 9,0569 & 29,8316 & 4,4833 & 5,3983 & 12,8759 & 4,1039 & 4,7510 & 10,2917 \\
\hline$k_{40}$ & 6,2979 & 9,5802 & 32,0916 & 4,5874 & 5,5899 & 13,6448 & 4,1594 & 4,8361 & 10,7363 \\
\hline$k_{41}$ & 6,2955 & 9,5765 & 32,0871 & 4,5876 & 5,5891 & 13,6355 & 4,1595 & 4,8359 & 10,7319 \\
\hline$k_{42}$ & 4,8190 & 6,9336 & 20,2283 & 4,0307 & 4,6136 & 9,8915 & 3,8483 & 4,3202 & 8,6963 \\
\hline$k_{43}$ & 6,2273 & 9,4304 & 31,4499 & 4,5704 & 5,5465 & 13,4009 & 4,1513 & 4,8163 & 10,6378 \\
\hline$k_{44}$ & 6,3085 & 9,6016 & 32,2220 & 4,5912 & 5,5958 & 13,6699 & 4,1608 & 4,8381 & 10,7413 \\
\hline$k_{45}$ & 5,9071 & 8,7083 & 27,7994 & 4,4881 & 5,3392 & 12,1190 & 4,1037 & 4,7002 & 10,0256 \\
\hline$k_{46}$ & 6,1479 & 9,2626 & 30,6991 & 4,5498 & 5,4979 & 13,1371 & 4,1419 & 4,7947 & 10,5351 \\
\hline$k_{47}$ & 4,9032 & 6,1075 & 9,7353 & 4,2283 & 4,6430 & 6,4923 & 3,9674 & 4,3387 & 6,4333 \\
\hline$k_{48}$ & 5,5175 & 7,3282 & 13,8304 & 4,4274 & 5,0938 & 8,4281 & 4,0856 & 4,6152 & 8,0360 \\
\hline$k_{49}$ & 5,3983 & 7,0496 & 12,6794 & 4,3826 & 4,9843 & 7,7763 & 4,0596 & 4,5528 & 7,7420 \\
\hline$k_{50}$ & 4,1693 & 4,8416 & 6,4214 & 3,9473 & 4,1245 & 5,2532 & 3,7811 & 3,9701 & 5,1307 \\
\hline$k_{51}$ & 4,9590 & 5,8642 & 8,0500 & 4,2955 & 4,7469 & 6,0560 & 4,0112 & 4,3788 & 6,0010 \\
\hline$k_{52}$ & 3,9433 & 4,2701 & 4,8442 & 3,8304 & 3,8975 & 4,2291 & 3,6587 & 3,6945 & 4,1370 \\
\hline$k_{53}$ & 6,0270 & 8,6333 & 20,9340 & 4,5508 & 5,4592 & 11,4580 & 4,1453 & 4,7876 & 10,0533 \\
\hline$k_{54}$ & 5,4194 & 6,9045 & 11,8371 & 4,4048 & 5,0495 & 7,7306 & 4,0669 & 4,5481 & 7,5478 \\
\hline
\end{tabular}


Tablo 4. $p=6$ ve $\% 10$ aykırı değer bulunması durumunda MSE değerleri

\begin{tabular}{|c|c|c|c|c|c|c|c|c|c|}
\hline \multirow[t]{2}{*}{$\mathbf{n}$} & \multicolumn{3}{|c|}{30} & \multicolumn{3}{|c|}{50} & \multicolumn{3}{|c|}{70} \\
\hline & $\mathbf{0 , 9 0}$ & 0,95 & 0,99 & 0,90 & 0,95 & 0,99 & 0,90 & 0,95 & 0,99 \\
\hline$\alpha$ & 12,9469 & 24,0652 & 120,7487 & 5,9058 & 10,4128 & 55,1169 & 4,7019 & 7,3899 & 38,5499 \\
\hline $\boldsymbol{\alpha}_{M}$ & 9,8879 & 19,4058 & 102,4783 & 5,2970 & 9,8616 & 47,0140 & 3,8450 & 6,9994 & 24,8972 \\
\hline $\boldsymbol{\alpha}_{\mathbf{G M}}$ & 6,6429 & 10,2284 & 35,8696 & 4,5179 & 5,6284 & 15,0807 & 3,9980 & 4,9502 & 11,3522 \\
\hline$k_{1}$ & 6,1348 & 9,2242 & 31,9138 & 4,3771 & 5,3474 & 14,0066 & 3,9116 & 4,7767 & 10,7705 \\
\hline$k_{2}$ & 5,0327 & 7,2022 & 23,4954 & 3,8997 & 4,6344 & 11,3810 & 3,5719 & 4,2704 & 9,1782 \\
\hline$k_{3}$ & 5,7670 & 8,5063 & 29,1448 & 4,2643 & 5,1299 & 13,2014 & 3,8395 & 4,6354 & 10,2990 \\
\hline$k_{4}$ & 4,9037 & 6,8348 & 22,7048 & 3,9667 & 4,5796 & 11,1621 & 3,6385 & 4,2519 & 8,9912 \\
\hline$k_{5}$ & 6,6028 & 10,1153 & 33,9654 & 4,5160 & 5,6168 & 15,0273 & 3,9968 & 4,9472 & 11,3175 \\
\hline$k_{6}$ & 4,6713 & 5,3385 & 9,6888 & 4,1475 & 4,6708 & 8,3945 & 3,7995 & 4,4272 & 7,7518 \\
\hline$k_{7}$ & 3,4131 & 3,9362 & 8,7683 & 3,1762 & 3,3964 & 6,4216 & 2,9817 & 3,3659 & 5,5975 \\
\hline$k_{8}$ & 4,2669 & 5,4693 & 15,2626 & 3,7152 & 4,1807 & 9,2110 & 3,4340 & 3,9796 & 7,7901 \\
\hline$k_{9}$ & 4,1047 & 5,1920 & 14,7021 & 3,6381 & 4,0203 & 8,8480 & 3,4028 & 3,8494 & 7,3992 \\
\hline$k_{10}$ & 5,0843 & 7,2398 & 23,5382 & 3,9755 & 4,6769 & 11,4195 & 3,6367 & 4,3042 & 9,2210 \\
\hline$k_{11}$ & 4,6296 & 5,2688 & 8,8958 & 4,1490 & 4,6655 & 8,2834 & 3,7994 & 4,4305 & 7,7118 \\
\hline$k_{12}$ & 5,6428 & 7,4818 & 16,8480 & 4,3814 & 5,2582 & 11,9371 & 3,9276 & 4,7757 & 9,9957 \\
\hline$k_{13}$ & 6,2374 & 9,3541 & 30,8988 & 4,4440 & 5,4823 & 14,0854 & 3,9630 & 4,8786 & 10,9306 \\
\hline$k_{14}$ & 4,2675 & 5,7597 & 18,3505 & 3,5854 & 4,1134 & 9,1588 & 3,3578 & 3,7544 & 6,7839 \\
\hline$k_{15}$ & 4,3774 & 6,1442 & 21,6407 & 3,6572 & 4,2656 & 10,4505 & 3,3609 & 3,8225 & 8,0614 \\
\hline$k_{16}$ & 2,9134 & 3,1468 & 4,7533 & 2,7874 & 3,0558 & 4,5871 & 2,7426 & 2,9870 & 4,2509 \\
\hline$k_{17}$ & 3,4003 & 3,8704 & 6,8381 & 3,1745 & 3,3886 & 6,0450 & 3,1612 & 3,3628 & 5,4752 \\
\hline$k_{18}$ & 4,2316 & 5,2648 & 9,1494 & 3,7099 & 4,1586 & 8,2364 & 3,4420 & 3,9698 & 7,5251 \\
\hline$k_{19}$ & 3,3677 & 3,6075 & 5,2777 & 3,2730 & 3,3950 & 4,6834 & 3,2127 & 3,3769 & 4,4268 \\
\hline$k_{20}$ & 5,8980 & 7,3759 & 11,0144 & 4,4262 & 5,2884 & 9,8459 & 3,9585 & 4,8075 & 9,0803 \\
\hline$k_{21}$ & 4,1703 & 4,9657 & 9,8960 & 3,6957 & 3,9946 & 6,9383 & 3,4847 & 3,8951 & 6,3623 \\
\hline$k_{22}$ & 6,2905 & 8,6920 & 16,8196 & 4,4745 & 5,4597 & 11,9447 & 3,9803 & 4,8770 & 10,1390 \\
\hline$k_{23}$ & 4,0692 & 4,8137 & 9,5204 & 3,6464 & 3,9004 & 6,7232 & 3,4541 & 3,8158 & 6,1427 \\
\hline$k_{24}$ & 6,3441 & 8,8448 & 17,8957 & 4,4822 & 5,4910 & 12,2074 & 3,9840 & 4,8910 & 10,2771 \\
\hline$k_{25}$ & 5,9910 & 8,7498 & 26,7876 & 4,3958 & 5,3733 & 13,4358 & 3,9393 & 4,8254 & 10,6296 \\
\hline$k_{26}$ & 5,0324 & 7,2010 & 23,4744 & 3,8996 & 4,6343 & 11,3792 & 3,5719 & 4,2704 & 9,1776 \\
\hline$k_{27}$ & 6,1444 & 9,0756 & 29,0208 & 4,4302 & 5,4440 & 13,9353 & 3,9552 & 4,8597 & 10,8476 \\
\hline$k_{28}$ & 5,3383 & 6,1084 & 7,5196 & 4,2940 & 4,8977 & 7,3279 & 3,8992 & 4,6154 & 7,1531 \\
\hline$k_{29}$ & 3,7785 & 4,2460 & 7,6656 & 3,5312 & 3,7342 & 6,2823 & 3,3851 & 3,6766 & 5,7527 \\
\hline$k_{30}$ & 6,0345 & 7,8970 & 12,8019 & 4,4245 & 5,2918 & 9,9063 & 3,9613 & 4,8005 & 9,0856 \\
\hline$k_{31}$ & 4,7634 & 5,9890 & 13,7475 & 3,9875 & 4,4989 & 9,1773 & 3,6709 & 4,2673 & 7,9979 \\
\hline$k_{32}$ & 5,9373 & 7,6593 & 11,9068 & 4,4052 & 5,2232 & 9,5690 & 3,9524 & 4,7672 & 8,8429 \\
\hline$k_{33}$ & 4,8790 & 6,1803 & 14,2088 & 4,0322 & 4,6005 & 9,4181 & 3,7038 & 4,3363 & 8,2303 \\
\hline$k_{34}$ & 5,3346 & 6,1037 & 7,5170 & 4,2925 & 4,8950 & 7,3243 & 3,8983 & 4,6134 & 7,1489 \\
\hline$k_{35}$ & 4,0506 & 4,5416 & 8,0772 & 3,7454 & 3,9823 & 6,6415 & 3,5663 & 3,9128 & 6,1752 \\
\hline$k_{36}$ & 5,9230 & 7,6320 & 11,8719 & 4,4009 & 5,2144 & 9,5464 & 3,9498 & 4,7618 & 8,8247 \\
\hline$k_{37}$ & 5,9692 & 7,7489 & 12,3987 & 4,4090 & 5,2508 & 9,7515 & 3,9526 & 4,7801 & 8,9583 \\
\hline$k_{38}$ & 4,8980 & 6,1664 & 14,0397 & 4,0575 & 4,6004 & 9,3370 & 3,7309 & 4,3448 & 8,1780 \\
\hline$k_{39}$ & 6,3704 & 9,7367 & 33,1266 & 4,4427 & 5,4848 & 14,7872 & 3,9443 & 4,8924 & 11,0354 \\
\hline$k_{40}$ & 6,6315 & 10,2026 & 35,4938 & 4,5157 & 5,6247 & 15,0681 & 3,9971 & 4,9487 & 11,3476 \\
\hline$k_{41}$ & 6,6289 & 10,2001 & 35,7128 & 4,5156 & 5,6240 & 15,0663 & 3,9969 & 4,9485 & 11,3467 \\
\hline$k_{42}$ & 5,3195 & 7,6866 & 23,9775 & 4,1171 & 4,9238 & 12,8115 & 3,7170 & 4,5841 & 10,0108 \\
\hline$k_{43}$ & 6,5612 & 10,0662 & 35,2219 & 4,5013 & 5,5948 & 14,9491 & 3,9896 & 4,9331 & 11,2946 \\
\hline$k_{44}$ & 6,6386 & 10,2199 & 35,8357 & 4,5172 & 5,6270 & 15,0755 & 3,9978 & 4,9496 & 11,3503 \\
\hline$k_{45}$ & 6,2107 & 9,3241 & 31,9492 & 4,4136 & 5,4077 & 14,1594 & 3,9395 & 4,8259 & 10,9002 \\
\hline$k_{46}$ & 6,4857 & 9,9155 & 34,6223 & 4,4855 & 5,5627 & 14,8239 & 3,9815 & 4,9165 & 11,2389 \\
\hline$k_{47}$ & 5,2158 & 6,5867 & 13,2224 & 4,1707 & 4,7942 & 9,7410 & 3,8016 & 4,5237 & 8,6811 \\
\hline$k_{48}$ & 5,8483 & 7,9240 & 18,2524 & 4,3702 & 5,2234 & 11,8797 & 3,9265 & 4,7655 & 10,0128 \\
\hline$k_{49}$ & 5,7153 & 7,6539 & 17,3583 & 4,3232 & 5,1220 & 11,3422 & 3,9041 & 4,7058 & 9,7385 \\
\hline$k_{50}$ & 4,3909 & 5,0681 & 8,5260 & 3,8851 & 4,2261 & 7,2913 & 3,5990 & 4,1435 & 6,9517 \\
\hline$k_{51}$ & 5,1692 & 6,1225 & 9,3635 & 4,1946 & 4,7351 & 7,3819 & 3,8342 & 4,4525 & 6,8526 \\
\hline$k_{52}$ & 4,0571 & 4,3351 & 5,6338 & 3,6337 & 3,7471 & 4,6582 & 3,5385 & 3,6603 & 4,4319 \\
\hline$k_{53}$ & 6,3435 & 9,2165 & 24,9397 & 4,4842 & 5,5192 & 13,8658 & 3,9836 & 4,9075 & 10,9265 \\
\hline$k_{54}$ & 5,6506 & 7,2727 & 14,2729 & 4,3075 & 5,0399 & 9,2610 & 3,9007 & 4,6178 & 8,1908 \\
\hline
\end{tabular}


Simülasyon çalışması ile elde edilen tablolardan çıkartılan sonuçlar ise aşağıda özetlenmiştir:

- Örneklem hacmi arttıkça tüm tablolarda EKK, M, GM ve tüm $k$ değerleri için RGME’ nin MSE değerleri azalmaktadır.

- Bağımsız değişken sayısı arttıkça tüm tahmin edicilerin MSE değerleri artmaktadır.

- Korelasyon şiddeti arttıkça tüm tahmin edicilerin MSE değeri artmaktadır.

- Bağımlı değişkende aykırı değer bulunduğu için M tahmin edicisi EKK tahmin edicisinden daha küçük MSE değerine sahiptir.

- Bağımsız değiş̧kende aykırı değer bulunduğu için GM tahmin edicisi EKK ve M tahmin edicilerinden daha küçük MSE değerine sahiptir.

- Tüm k değerleri için RGME’ lerin MSE değerleri GM tahmin edicisinin MSE değerlerinden daha küçüktür.

- Tablo 1 ve 2'de görüldüğ̈̈ gibi $\mathrm{p}=4$ olması durumunda 0,99 korelasyon değeri için en küçük MSE değeri $k_{52}$ 'nin kullandığı RGME' dir.

- $\mathrm{p}=4$ ve $\% 5$ aykırı değer için 0,90 ve 0,95 korelasyon değerlerinde $k_{16}$ 'nın kullanıldı̆̆ı RGME en küçük MSE değerine sahiptir.

- Tablo 1' de 0,90 korelasyon değerinde GM tahmin edicisi EKK tahmin edicisinin MSE değerini n=30 iken \%70 iyileştirirken $k_{16}$ 'nın kullanıldığı RGME \%88 iyileştirmiştir. Ayrıca n=70 için GM tahmin edicisi \%61, RGME ise \%74 iyileştirmektedir.

- 0,99 korelasyon için en küçük MSE değeri olan $k_{52}$ 'nin kullanıldığı RGME ile EKK tahmin edicisinin MSE değerini \%98 iyileştirirken $k_{16}$ 'nın kullanıldığı RGME ise \%97 iyileştirmektedir.

- Tablo 2' de yani p=4 ve \%10 aykırı değer olması durumda en küçük MSE değeri 0,90 korelasyon için $k_{16}$ ' nın kullanıldığ RGME' ye, 0,95 korelasyon için $\mathrm{n}=30$ ve 50 iken $k_{19}$ ' un kullanıldığı RGME' ye, n=70 iken $k_{16}$ ' nın kullanıldığı RGME' ye ve 0,99 korelasyonda ise $k_{52}$ ' nin kullanıldığı RGME' ye aittir.

- 0,90 korelasyon değeri için $\mathrm{n}=30$ olması durumunda RGME, EKK tahmin edicisinin MSE’ sini \%85 iyileştirirken, $\mathrm{n}=70$ olması durumunda $\% 72$ iyileştirmektedir.

- 0,99 korelasyon değeri için ise $k_{52}$ ' nin kullanıldığı RGME, $\mathrm{n}=30$ olması durumunda EKK tahmin edicisinin MSE değerini $\% 96$ ve $n=70$ olması durumunda ise $\% 90$ iyileştirmektedir.

- Tablo 3 ve 4 'te görüldüğü gibi $p=6$ olması durumunda $\% 5$ ve $\% 10$ aykırı değer için seçilen tüm korelasyon değerlerinde en küçük MSE değeri $k_{16}$ ' nın kullanıldığı RGME' ne aittir.

- Tablo 3'e göre $\mathrm{n}=30$ olması durumunda 0,90 korelasyon için EKK tahmin edicisi GM tahmin edicisi ile $\% 57$ ve RGME ile $\% 81$ iyileştirilmiştir. $n=70$ olması durumunda GM tahmin edicisi ile $\% 26$, RGME ile \%51 iyileştirilmiştir.

- 0,99 korelasyon değeri için $\mathrm{n}=30$ olması durumunda EKK tahmin edicisinin MSE değeri GM tahmin edicisi ile \%76, RGME ile \%97 iyileştirilmiş̧ir. Ayrıca n=70 olması durumunda ise GM tahmin edicisi $\% 82$, RGME \%94 iyileştirmektedir.

- Tablo 4' teki $\mathrm{p}=6$ iken $\% 10$ aykırı değer olması durumunda 0,90 korelasyon değerinde $\mathrm{n}=30$ için EKK tahmin edicisinin MSE değeri GM tahmin edicisi ile \% 49, RGME ile \%77 ayrıca $\mathrm{n}=70$ olmas1 durumunda ise GM tahmin edicisi ile \%15, RGME ile \%42 iyileştirilmiştir.

- 0,99 korelasyon değeri için ise EKK tahmin edicisinin MSE değeri $\mathrm{n}=30$ için GM tahmin edicisi ile $\% 70$, RGME ile \%96, n=70 olması durumunda GM tahmin edicisi ile \%70, RGME ile \%89 iyileştirilmiştir.

- Korelasyon değerinin artması ile RGME’nin EKK tahmin edicisinin MSE değerini iyileştirme oranı artmaktadır. 


\begin{tabular}{|c|c|c|}
\hline & $\begin{array}{l}\text { BŞEÜ Fen Bilimleri Dergisi } \\
8(1), 203-216,2021\end{array}$ & $\begin{array}{r}\text { BSEU Journal of Science } \\
\text { https://doi.org/10.35193/bseufbd.877176 }\end{array}$ \\
\hline $\begin{array}{l}\text { ONIVERSITESS } \\
\text { ONESE }\end{array}$ & & 2458-7575 (https://dergipark.org.tr/tr/pub/bseufbd) \\
\hline
\end{tabular}

- Örneklem hacmi arttıkça GM tahmin edicisi ve RGME' nin EKK tahmin edicisinin MSE değerini iyileştirme oranı azalmaktadır.

- Aykırı değer oranının artması durumunda tahmin edicilerin EKK tahmin edicisinin MSE değerini iyileştirme oranı azalmaktadır.

- Değişken sayısının artması durumunda yine tahmin edicilerin EKK tahmin edicisinin MSE değerini iyileştirme oranları azalmaktadır.

\section{B. Gerçek Veri}

$\mathrm{Bu}$ bölümde elde edilen simülasyon sonuçların desteklemek amacıyla gerçek veri seti örneğinde de tahmin edicilerin performansları MSE kriterine göre karşılaştırılmış̧ır. Bu amaçla Brownlee [29] tarafindan verilen stackloss verisi kullanılmıştır. Amonyağın (NH) nitrik aside (HNO) oksidasyonu için bir tesisin 21 gün işletilmesiyle elde edilen veri setinde üç bağımsız değişken bulunmaktadır. Bu değişkenler soğutma suyunun sıcaklığı, hava akımı ve asit konsantrasyonunu göstermektedir. Bağımlı değişken ise absorbe edilmeden bitkiye giden amonyak ölçüsüdür. Bu ölçü olarak amonyak miktarının on katı alınmış ve bu şekilde tesisin verimliliği ölçülmeye çalışılmıştır. Bu veri setinde EKK, ME, GM ve çalışmada kullanılan farklı yanlılık parametreleri ile RE, RME ve RGME tahmin edicilerinin MSE değerleri hesaplanmıştır. Elde edilen sonuçlar ise Tablo 5' te verilmiştir.

Tablo 5.Stackloss verisine ait tahmin edicilerin MSE değerleri

\begin{tabular}{|c|c|c|c|c|c|c|c|c|}
\hline & & $k_{1}$ & $k_{2}$ & $k_{3}$ & $k_{4}$ & $k_{5}$ & $k_{6}$ & $k_{7}$ \\
\hline $\boldsymbol{\alpha}$ & 0,2428 & 0,20923 & 0,19221 & 0,18943 & 0,17614 & 0,24275 & 0,17074 & 0,16865 \\
\hline $\boldsymbol{\alpha}_{M}$ & 0,2238 & 0,19344 & 0,17640 & 0,17507 & 0,16258 & 0,22381 & 0,15962 & 0,15636 \\
\hline \multirow[t]{2}{*}{$\boldsymbol{\alpha}_{\mathrm{GM}}$} & 0,1998 & 0,16385 & 0,13858 & 0,14185 & 0,12658 & 0,19977 & 0,13032 & 0,12042 \\
\hline & $k_{8}$ & $k_{9}$ & $k_{10}$ & $k_{11}$ & $k_{12}$ & $k_{13}$ & $k_{14}$ & $k_{15}$ \\
\hline$\alpha$ & 0,17024 & 0,17232 & 0,19223 & 0,17030 & 0,19188 & 0,19908 & 0,19221 & 0,24275 \\
\hline $\boldsymbol{\alpha}_{M}$ & 0,15920 & 0,15949 & 0,17643 & 0,15926 & 0,17816 & 0,18295 & 0,17677 & 0,17640 \\
\hline \multirow[t]{2}{*}{$\boldsymbol{\alpha}_{\mathrm{GM}}$} & 0,12996 & 0,12373 & 0,13863 & 0,13003 & 0,15002 & 0,15030 & 0,15356 & 0,15315 \\
\hline & $k_{16}$ & $k_{17}$ & $k_{18}$ & $k_{19}$ & $k_{20}$ & $k_{21}$ & $k_{22}$ & $k_{23}$ \\
\hline $\boldsymbol{\alpha}$ & 0,15221 & 0,16864 & 0,17024 & 0,19676 & 0,24063 & 0,24509 & 0,24204 & 0,21189 \\
\hline $\boldsymbol{\alpha}_{M}$ & 0,14102 & 0,15636 & 0,15920 & 0,18128 & 0,22194 & 0,18851 & 0,22316 & 0,19482 \\
\hline \multirow[t]{2}{*}{$\boldsymbol{\alpha}_{\mathrm{GM}}$} & 0,10142 & 0,12042 & 0,13000 & 0,15525 & 0,19849 & 0,16078 & 0,19930 & 0,16802 \\
\hline & $k_{24}$ & $k_{25}$ & $k_{26}$ & $k_{27}$ & $k_{28}$ & $k_{29}$ & $k_{30}$ & $k_{31}$ \\
\hline$\alpha$ & 0,24182 & 0,18745 & 0,24275 & 0,20006 & 0,24110 & 0,21205 & 0,24153 & 0,21801 \\
\hline $\boldsymbol{\alpha}_{M}$ & 0,22297 & 0,17162 & 0,22381 & 0,18496 & 0,22229 & 0,19594 & 0,22265 & 0,20133 \\
\hline \multirow[t]{2}{*}{$\boldsymbol{\alpha}_{\mathrm{GM}}$} & 0,19915 & 0,14009 & 0,13858 & 0,15812 & 0,19867 & 0,17053 & 0,19887 & 0,17641 \\
\hline & $k_{32}$ & $k_{33}$ & $k_{34}$ & $k_{35}$ & $k_{36}$ & $k_{37}$ & $k_{38}$ & $k_{39}$ \\
\hline$\alpha$ & 0,24156 & 0,21740 & 0,24110 & 0,21209 & 0,24156 & 0,24152 & 0,21803 & 0,24275 \\
\hline $\boldsymbol{\alpha}_{M}$ & 0,22266 & 0,20125 & 0,22229 & 0,19597 & 0,22266 & 0,22265 & 0,20135 & 0,22381 \\
\hline \multirow[t]{2}{*}{$\boldsymbol{\alpha}_{\mathrm{GM}}$} & 0,19879 & 0,17793 & 0,19867 & 0,17057 & 0,19879 & 0,19886 & 0,17643 & 0,19977 \\
\hline & $k_{40}$ & $k_{41}$ & $k_{42}$ & $k_{43}$ & $k_{44}$ & $k_{45}$ & $k_{46}$ & $k_{47}$ \\
\hline$\alpha$ & 0,24275 & 0,24275 & 0,24274 & 0,24248 & 0,24275 & 0,23451 & 0,24221 & 0,24096 \\
\hline $\boldsymbol{\alpha}_{M}$ & 0,22381 & 0,22381 & 0,22380 & 0,22357 & 0,22381 & 0,21642 & 0,22332 & 0,22219 \\
\hline \multirow[t]{2}{*}{$\boldsymbol{\alpha}_{\mathrm{GM}}$} & 0,19977 & 0,19977 & 0,19976 & 0,19948 & 0,19977 & 0,19101 & 0,19920 & 0,19810 \\
\hline & $k_{48}$ & $k_{49}$ & $k_{50}$ & $k_{51}$ & $k_{52}$ & $k_{53}$ & $k_{54}$ & \\
\hline$\alpha$ & 0,24215 & 0,24200 & 0,23827 & 0,20650 & 0,15906 & 0,24258 & 0,22485 & \\
\hline $\boldsymbol{\alpha}_{M}$ & 0,22327 & 0,22311 & 0,21978 & 0,19034 & 0,14390 & 0,22366 & 0,20693 & \\
\hline $\boldsymbol{\alpha}_{\mathrm{GM}}$ & 0,19922 & 0,19901 & 0,19564 & 0,17287 & 0,11827 & 0,19963 & 0,18617 & \\
\hline
\end{tabular}

Tablo 5 incelendiğinde veri setinde bağımlı değişkende aykırı değer bulunduğundan dolayı ME, EKK tahmin edicisinden daha etkin ayrıca bağımsız değişkende de aykırı değer bulunduğundan dolayı GM tahmin edicisi ise hem EKK hem de ME' den daha etkin sonuçlar vermiş̧ir. Benzer şekilde tüm yanlılık parametrelerine bağlı RME' ler, RE' lerden daha etkin ve RGME' ler ise RE ve RME' lerden daha küçük MSE değerlerine sahiptirler. Çoklu iç ilişki bulunan veri setinde tüm yanlılık parametreleri için RE' ler, EKK tahmin edicisinden, RME' ler, ME' den ve RGME' ler ise GM tahmin edicisinden daha küçük MSE değerlerine sahiptirler. RE, RME ve RGME tahmin edicilerinin MSE değerleri tek tek incelendiğinde üç tahmin edici için kendi içlerinde en küçük MSE değeri $k_{16}$ ile hesaplanan tahmin edicilere aittir. Tüm MSE değerlerine bakıldığında ise en küçük MSE değeri $\mathrm{k}_{16}$ ' ya bağl1 RGME tahmin edicisine aittir. 


\section{SONUÇLAR}

Bu çalışmada Ridge tahmin edicisinin performansını etkileyen yanlılık parametresinin farklı tahmin edicileri üzerinde durulmuştur. Yapılan çalışmalar incelendiğinde yanlılık parametresinin performansı sadece çoklu iç ilişki bulunan veri setleri üzerinde yapılan simülasyon çalışmalarında tahmin edicilerin performansları karşılaştırılmıştır.

Çoklu iç ilişki bulunan veri setlerinde daha etkin sonuçlar elde edebilmek amacıyla Ridge tahmin edicisi önerilmiştir. Fakat uygulamada çoklu iç ilişki problemi, sıklıkla karşılaşılan diğer bir problem olan aykırı değer problemi ile birlikte görülmektedir. Bu iki problemin ortak çözümleri için yapılan çalışmalarda sağlam Ridge tahmin edicileri önerilmiştir. Bu tahmin edicilerden en yaygın olarak bilineni RME' dir. Fakat bu tahmin edici bağımsız değişkende aykırı değer bulunması durumunda etkinliğini kaybetmektedir. Bu amaçla RGME önerilmiştir.

Önerilen sağlam Ridge tahmin edicilerinde genellikle Hoerl ve Kennard [4] tarafından önerilen yanlılık parametresinin tahmin edicisi kullanılmıştır. RE' de bu yanlılık parametresinin tahmini için alternatif birçok yanlılık parametresi tahmin edicileri önerilmiştir. Fakat önerilen diğer parametre tahmin edicilerinin sağlam Ridge tahmin edicilerindeki performansları karşılaştırılmamıştır. Bu amaçla her iki değişkende de aykırı değer bulunması ve çoklu iç ilişki problemi olan veri setlerinde RE ve RME' den daha etkin sonuçlar veren RGME' de farklı yanlılık parametrelerinin performansları karşılaştırılmıştır. Yapılan simülasyon çalışması ve gerçek veri örneğinin sonuçları göstermiştir ki önerilen yanlılık parametreleri RGME' ne olumsuz bir etki göstermemektedir. Tüm yanlılık parametreleri ile RGME, EKK, ME ve GM tahmin edicilerinden daha etkin sonuçlar vermektedir.

Yapılan bu çalışmada M tipi tahmin ediciler üzerinde durulmuştur. Bu çalışmaya ek olarak diğer sağlam Ridge tahmin edicilerinde farklı yanlılık parametrelerinin performansları incelenebilir. Veri setinde aykırı değer bulunması durumunda kullanılabilecek sağlam tahmin edicilere bağlı olarak yeni yanlılık parametresi için tahmin ediciler önerilebilir.

\section{TEŞEKKÜR}

Bu çalışma, Eskişehir Osmangazi Üniversitesi Bilimsel Araştırma Projeleri (ESOGÜBAP) Komisyonu tarafından 2020-19A102 nolu proje olarak desteklenmiştir.

\section{KAYNAKLAR}

[1] Huber, P. J. (1964). Robust estimation of a location parameter. The Annals of Mathematical Statistics Theory and Methods, 53 (1), 73-101.

[2] Mallows, C. L. (1975). On some topics in Robustness. Unpublished Memorandum, Bell Telephone Laboratories, Murray Hill, NJ.

[3] Handschin, E., Schweppe, F. C., Kohlas, J. \& Fiechter, A. (1975). Bad data analysis for power system state estimation. IEEE Transactions on Power Apparatus and Systems, 4 (2), 105-123.

[4] Hoerl, A. E. \& Kennard, R. W. (1970). Ridge regression: biased estimation for nonorthogonal problems. Technometrics, 12, 55-67.

[5] Theobald, C.M. (1974). Generalization of mean square error applied to ridge regression. Journal of the Royal Statistical Society, ser B (36), 103-106.

[6] Hoerl, A.E., Kennard, R.W. \& Baldwin, K.F. (1975). Ridge regression: some simulation. Communications in Statistics, 4, 105-123.

[7] Lawless, J. F. \& Wang, P. A. (1976). Simulation study of ridge and other regression estimators. Communications in Statistics, Theory and Methods, 5, 307-323.

[8] Hocking, R. R., Speed, F. M. \& Lynn, M. J. (1976). A class of biased estimators in linear regression. Technometrics, 18, 425-438.

[9] Kibria, B.M.G. (2003). Performance of some new ridge regression estimators. Communications in Statistics-Theory and Methods, 32, 419-435.

[10] Khalaf, G. \& Shukur, G. (2005). Choosing ridge parameters for regression problems. Communications in Statistics-Theory and Methods, A34, 1177-1182.

[11] Alkhamisi, M., Khalaf, G. \& Shukur, G. (2006). Some modifications for choosing ridge parameters. Communications in Statistics-Theory and Methods, 35(11), 2005-2020.

[12] Alkhamisi, M. A. \& Shukur, G. (2007). A Monte Carlo study of recent ridge parameters. Communications in Statistics-Simulation and Computation ${ }^{\circledR}, 36(3), 535-547$. 
[13] Muniz, G. \& Kibria, B. G. (2009). On some ridge regression estimators: An empirical comparisons. Communications in Statistics-Simulation and Computation ${ }^{\circledR}, 38(3), 621-630$.

[14] Al-Hassan, Y. M. (2010). Performance of a new ridge regression estimator. Journal of the Association of Arab Universities for Basic and Applied Sciences, 9(1), 23-26.

[15] Muniz, G., Kibria, B. M. G., Mansoon, K. \& Shukur, G. (2012). On developing ridge regression parameters: a graphical investigation. Sort Stat Oper. Res. Trans, 36 (2), 115-138.

[16] Dorugade, A. V. (2014). New ridge parameters for ridge regression. Journal of the Association of Arab Universities for Basic and Applied Sciences, 15, 94-99.

[17] Karaibrahimoğlu, A., Asar, Y. \& Genç, A. (2014). Some new modifications of Kibria's and Dorugade's methods: An application to Turkish GDP data. Journal of the Association of Arab Universities for Basic and Applied Sciences, 20, 89-99.

[18] Asar, Y. \& Genç, A. (2017). A note on some new modifications of ridge estimators. Kuwait J. Sci.,44 (3), 75-82.

[19] Silvapulle, M. J. (1991). Robust ridge regression based on an m estimator. Australian Journal of Statistics, 33 (3), 319-333.JJ

[20] Arslan, O. \& Billor, N. (1996). Robust ridge estimation based on the gm estimators. Journal of Mathematical and Computational Science, 9(1), 1-9.

[21] Altın Yavuz, A. (2019). A New Modification of Ridge Parameter for Regression Problems: A Monte Carlo Simulation Study, Turkiye Klinikleri Journal of Biostatistics, 11 (3), 173-188.

[22] Işılar, M. (2020). Çoklu Lineer Regresyon Modelinde Liu tipi GM Tahmin Edicisi, Yayımlanmamış Yüksek Lisans Tezi, Eskişehir Osmangazi Üniversitesi, Eskişehir.

[23] Simpson, D. G., Rubbert, D. \& Carrol, R. J. (1992). On one-step Gm estimates and stability of inferences in linear regression. Journal of the American Statistical Association, 87, 439-450.

[24] Farrar, D. E. \& Glauber, R. R. (1967). Multicollinearity in regression analysis: The problem revisited. The Review of Economics and Statistics, 49 (1), 92-107.

[25] Silvey, S. D. (1969). Multicollinearity and imprecise estimation. Journal of the Royal Statistical Society: Series B (Methodological), 31 (3), 539-552.

[26] McDonald, G. C. \& Galarneau, D. I. (1975). A Monte Carlo evaluation of ridge-type estimators. Journal of the American Statistical Association, 70 (350), 407-416.

[27] Newhouse, J. P. \& Oman, S. D. (1971). An evaluation of ridge estimators, Rand Corporation (p-716-PR) Santa Monica, 1-16.

[28] R Core Team (2014). R: A language and environment for statistical computing. Vienna, Austria: R Foundation for statistical computing.

[29] Brownlee, K. A. (1965). Statistical Theory and Methodology in Science and Engineering 2nd ed, John \& Sons, New York. 